Supporting Information

\title{
Suspended graphene membranes with attached silicon proof masses as piezoresistive NEMS accelerometers
}

Xuge Fan, ${ }^{*}{ }^{\dagger}$ Fredrik Forsberg, ${ }^{~}$ Anderson D. Smith, ${ }^{\S}$ Stephan Schröder,${ }^{\dagger}$

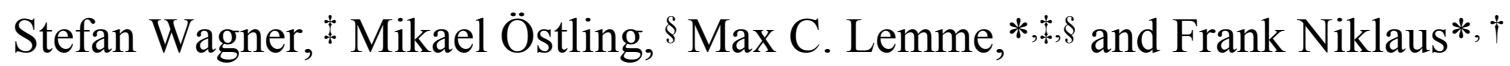

†Department of Micro and Nanosystems, School of Electrical Engineering and Computer Science, KTH Royal Institute of Technology, SE-10044 Stockholm, Sweden.

$\$$ Faculty of Electrical Engineering and Information Technology, RWTH Aachen University, Otto-Blumenthal-Str. 25, 52074 Aachen, Germany.

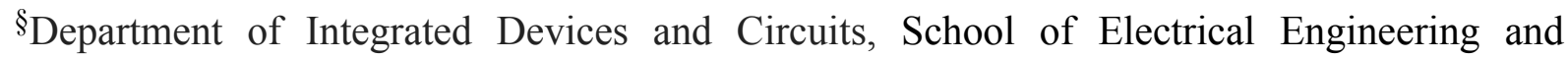
Computer Science, KTH Royal Institute of Technology, SE-164 40 Kista, Sweden.

"Scania Tekniskt Centrum, 15148 Södertälje, Sweden.

*email:xuge@eecs.kth.se, lemme@amo.de, frank.niklaus@eecs.kth.se 
This PDF file includes:

Equation (S1-S9). The equivalent resistance model of our devices.

Figure S1. High magnification SEM images of a graphene device.

Figure S2. SEM images of the backside of fabricated graphene devices.

Figure S3. Demonstration of release of the proof masses using white light interferometry.

Figure S4. Measurement of static displacement of the released proof masses in relation to the substrate surface using white light interferometry.

Figure S5. Raman spectroscopy of the double-layer graphene.

Figure S6. Measurement setup and circuit.

Figure S7. Force-displacement measurements of suspended graphene membranes with attached proof mass using AFM tip indentation.

Table S1. Graphene device dimensions and extracted resistances of the different graphene sections of the device.

Table S2. Displacement of the suspended silicon proof mass at different applied AFM indentation forces. 


\section{Equation (S1-S9). The equivalent resistance model of our devices.}

The change of the overall resistance $\mathrm{R}$ of a graphene device as a result of a change in the strain in the suspended graphene sections, caused by a deflection of the proof-mass due to forces acting on the mass, can be approximated by

$\Delta \mathrm{R}=\frac{1 U}{A \mathrm{I}}$

where $\mathrm{U}$ is the measured output voltage, $\mathrm{I}$ is the applied input current, and $\mathrm{A}$ is the amplification factor of the amplifier in the measurement circuit. According to equation (3), a change in strain in the suspended graphene sections with a corresponding resistance change $\Delta \mathrm{R}\left(\Delta \mathrm{R}_{7}\right.$ and $\left.\Delta \mathrm{R}_{5}\right)$ of the suspended graphene sections, the following equations can be obtained:

$$
R_{6}^{\prime}=\frac{1}{\frac{2}{\mathrm{R}_{7}+\Delta \mathrm{R}_{7}}+\frac{1}{\mathrm{R}_{8}}}
$$

Because $\Delta R_{7} \ll R_{7}$, equation ( $\left.\mathrm{S} 2\right)$ can be simplified to

$$
R_{6}^{\prime}=\frac{1}{\frac{2}{R_{7}+\Delta R_{7}}+\frac{1}{R_{8}}} \approx R_{6}
$$

Accordingly, equations (2) and (1) respectively result in

$\mathrm{R}_{4}^{\prime}=2\left(\mathrm{R}_{5}+\Delta \mathrm{R}_{5}\right)+\mathrm{R}_{6}^{\prime} \approx 2\left(\mathrm{R}_{5}+\Delta \mathrm{R}_{5}\right)+\mathrm{R}_{6}$

$R_{2}^{\prime}=\frac{R_{3} \times R_{4}^{\prime}}{R_{3}+2 R_{4}^{\prime}}$

$R^{\prime}=2 R_{1}+R_{2}^{\prime}$

According to equations (2) and (S4),

$\Delta R_{4}=R_{4}^{\prime}-R_{4} \approx 2 \Delta R_{5}$

According to equations (1), (S5) and (S6),

$\Delta \mathrm{R}=R_{2}^{\prime}-R_{2} \approx \frac{R_{3}^{2} \times \Delta R_{4}}{\left(R_{3}+2 R_{4}\right)^{2}}$

According to equations (S7) and (S8), 


$$
\Delta R_{5} \approx \Delta R \times\left(\frac{1}{2}+\frac{2 R_{4}}{R_{3}}+\frac{2 R_{4}^{2}}{R_{3}^{2}}\right)
$$
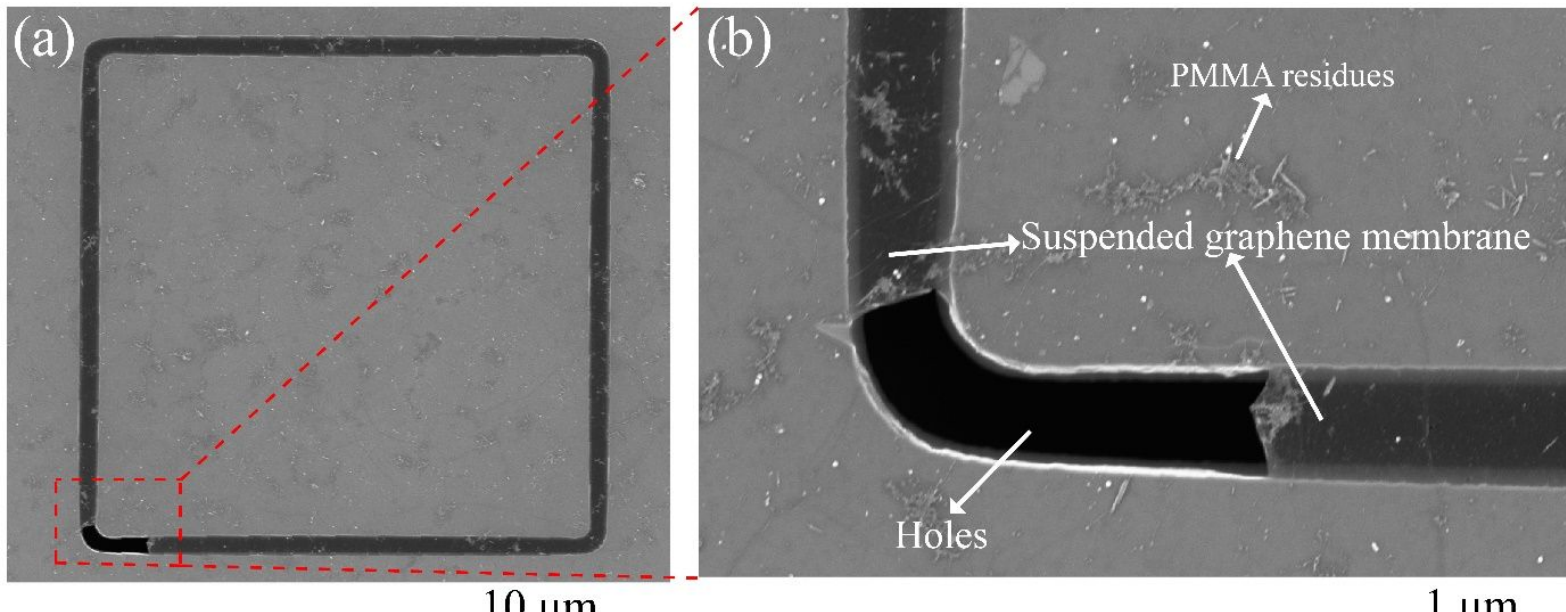

\section{$10 \mu \mathrm{m}$}

Figure S1. High magnification SEM images of a graphene device. (a) SEM image of a graphene device with a $1 \mu \mathrm{m}$ wide trench and a proof mass size of $40 \mu \mathrm{m} \times 40 \mu \mathrm{m} \times 16.4 \mu \mathrm{m}$. (b) A close-up view of (a) of the suspended graphene membrane with a hole and some PMMA residues on the double-layer graphene surface. 

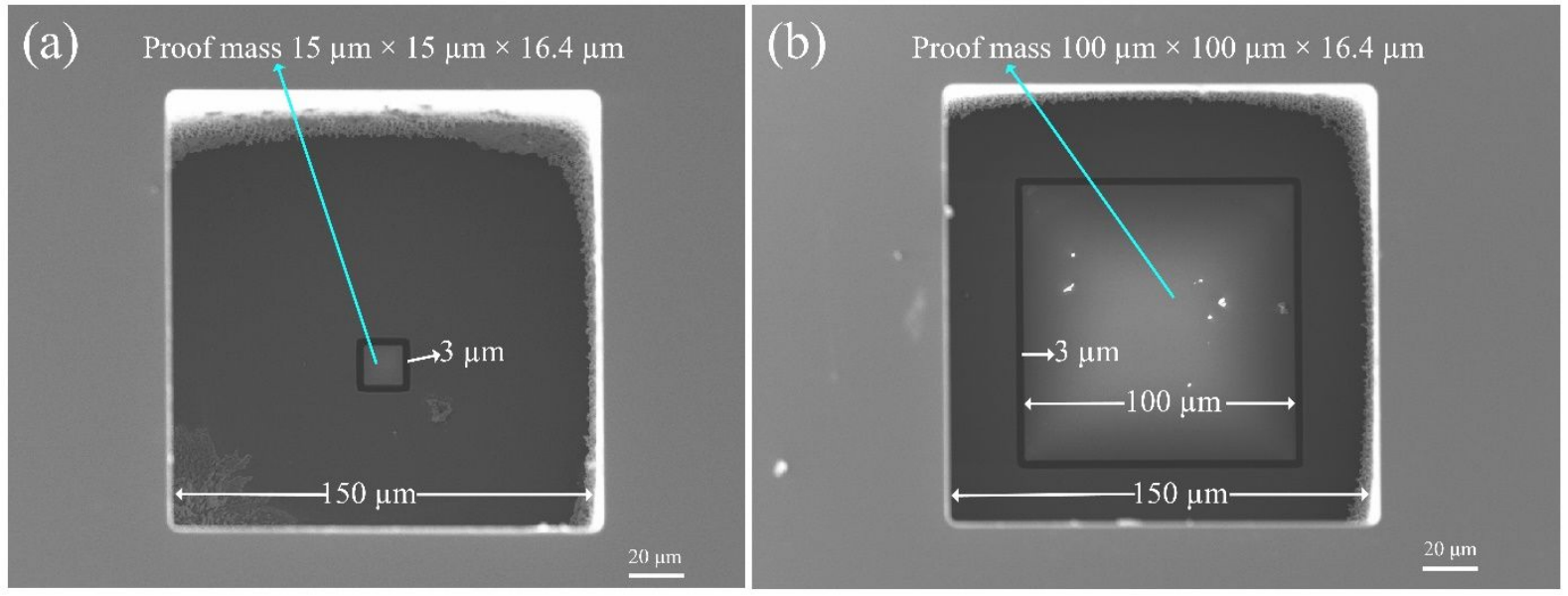

Figure S2. SEM images of the backside of fabricated graphene devices. (a) SEM image of

a graphene device with a $3 \mu \mathrm{m}$ wide trench and a proof mass size of $15 \mu \mathrm{m} \times 15 \mu \mathrm{m} \times$ $16.4 \mu \mathrm{m}$. (b) SEM image of a graphene device with a $3 \mu \mathrm{m}$ wide trench and a proof mass size of $100 \mu \mathrm{m} \times 100 \mu \mathrm{m} \times 16.4 \mu \mathrm{m}$. The SEM images of these devices were taken after the proof masses were released and suspended on the double-layer graphene membranes by removing the $\mathrm{BOX}\left(\mathrm{SiO}_{2}\right)$ layer in the areas of the trench and the proof mass using etching from the wafer backside. 

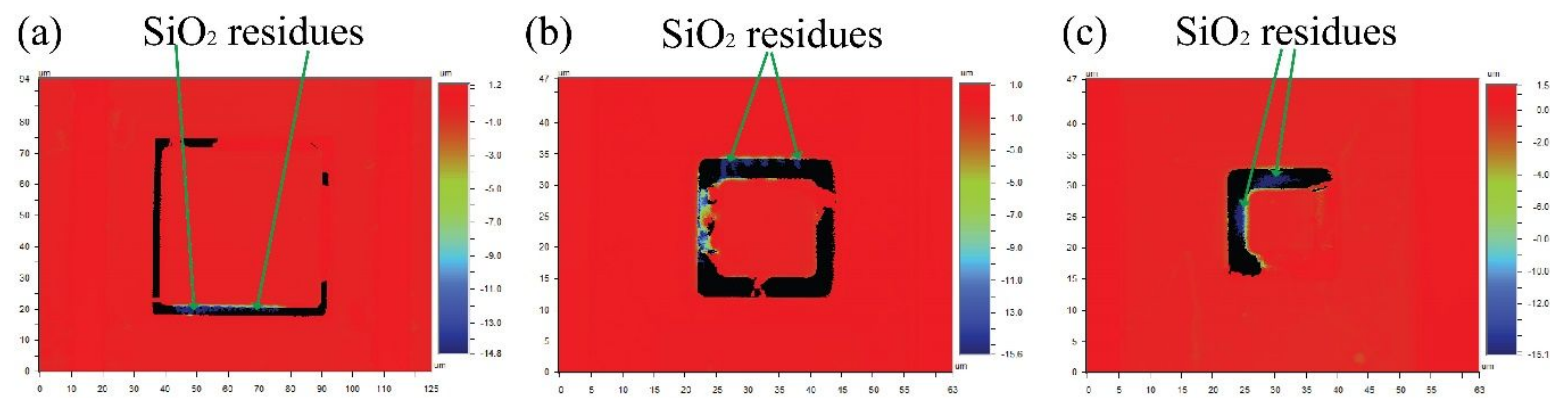

(d) $\quad \mathrm{No} \mathrm{SiO}_{2}$ residues

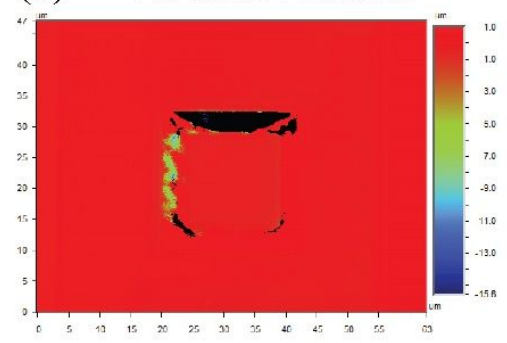

(e) $\quad \mathrm{No}^{\mathrm{SiO}} 2$ residues

(f) $\quad \mathrm{No}^{\mathrm{SiO}} 2$ residues
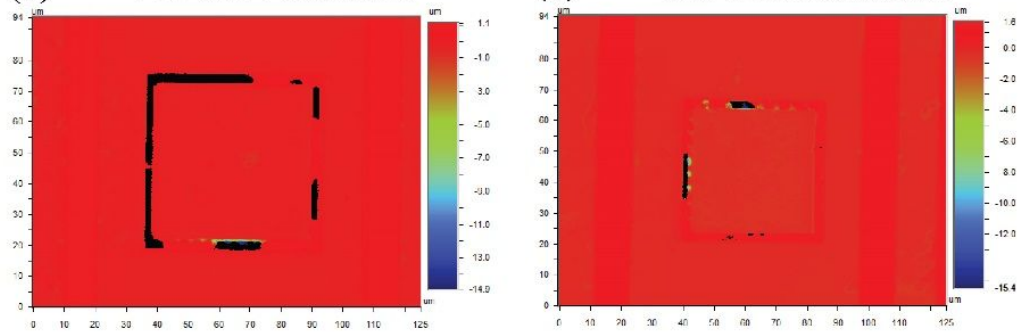

Figure S3. Demonstration of release of the proof masses using white light interferometry.

The release of the silicon proof masses by using a precisely adjusted vapor HF etching step was further confirmed using white light interferometry imaging to a depth of $\sim 17 \mu \mathrm{m}$ below the substrate surface. In this way residues of the $\mathrm{BOX}\left(\mathrm{SiO}_{2}\right)$ layer in the trenches became visible. The red patches over the trench areas indicate the suspended graphene membranes while the black areas over trench areas indicate holes in the graphene membranes over the trench. The blue area in the images depict residues of the $\mathrm{BOX}\left(\mathrm{SO}_{2}\right)$ layer in the trenches. (a) - (c), A few $\mathrm{SiO}_{2}$ residues (dark blue colour) that partly connect the silicon proof mass with the handle substrate are visible in the trenches, showing that these proof masses are not fully released. (d) - (f), $\mathrm{No}^{\mathrm{SiO}} 2$ residues remain (no dark blue colour), confirming that the silicon proof mass is fully released. It should be noted that slightly different vapour HF etching times were used for the devices in (a-f). 
(a)

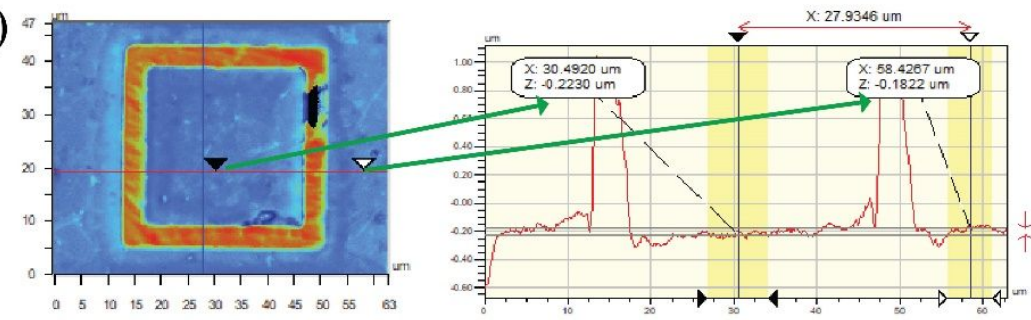

(b)
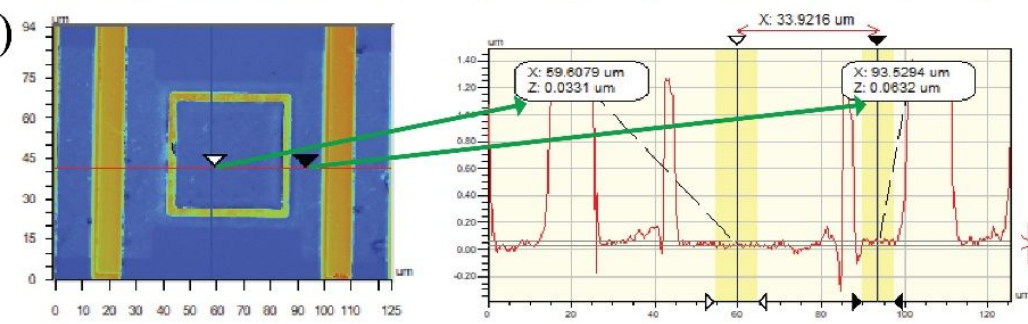

(c)
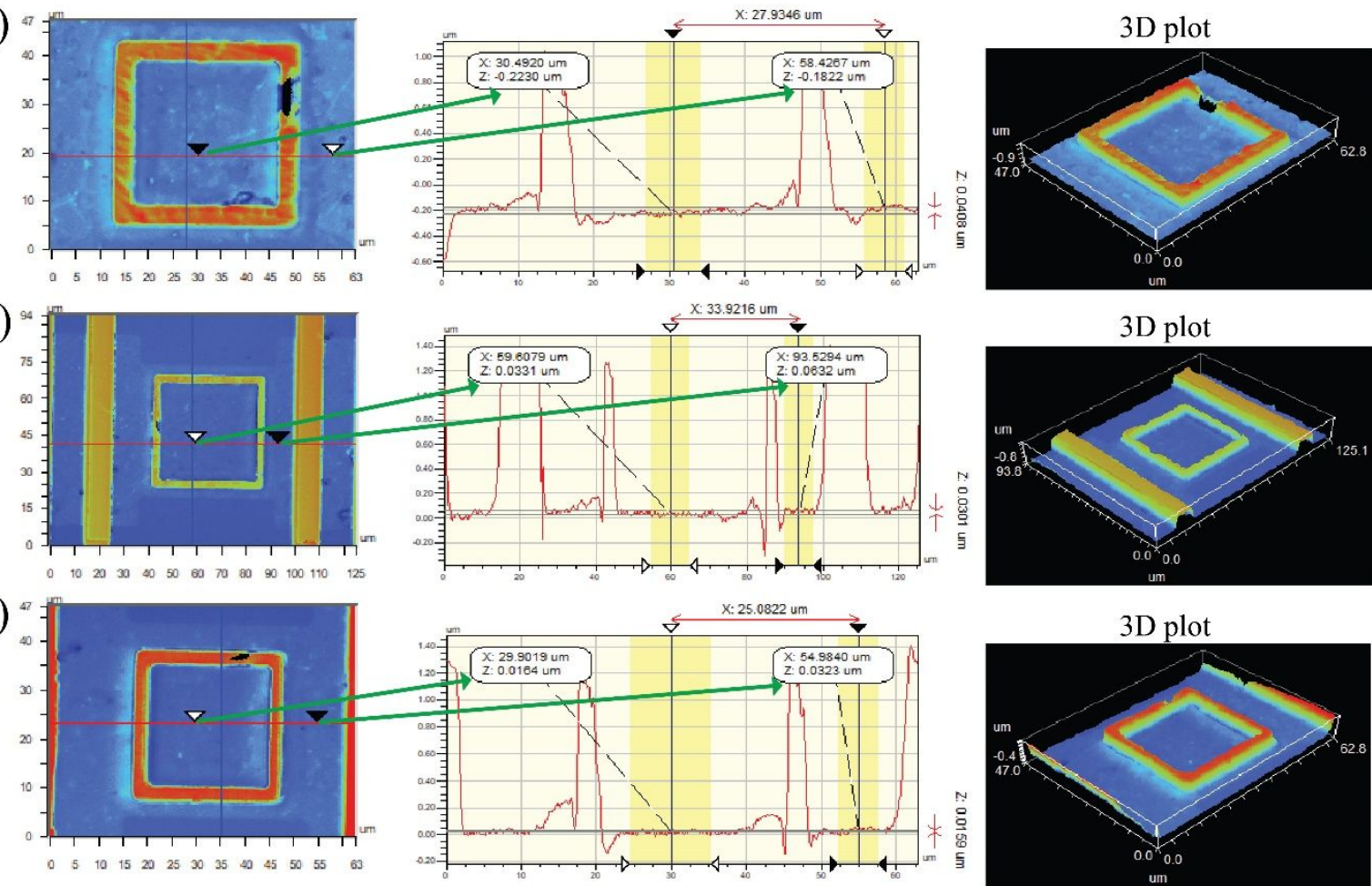

3D plot

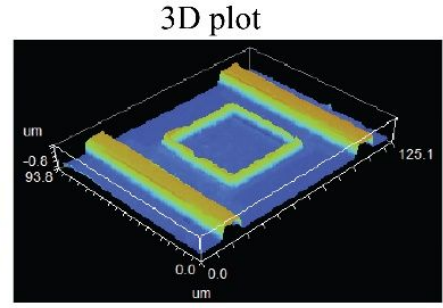

3D plot

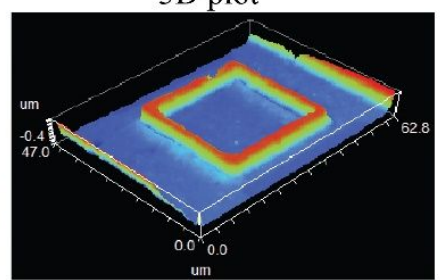

Figure S4. Measurement of static displacement of the released proof masses in relation to the substrate surface using white light interferometry. (a) Measurement of the top $\mathrm{SiO}_{2}$ surface and the corresponding 3D plot of a device with a $4 \mu \mathrm{m}$ wide trench and a silicon proof mass size of $30 \mu \mathrm{m} \times 30 \mu \mathrm{m} \times 16.4 \mu \mathrm{m}$. (b) Measurement of the top $\mathrm{SiO}_{2}$ surface and the corresponding 3D plot of a device with a $3 \mu \mathrm{m}$ wide trench and a silicon proof mass size of $40 \mu \mathrm{m} \times 40 \mu \mathrm{m} \times 16.4 \mu \mathrm{m}$. (c) Measurement of the top $\mathrm{SiO}_{2}$ surface and the corresponding 3D plot of a device with a $3 \mu \mathrm{m}$ wide trench and a silicon proof mass size of $25 \mu \mathrm{m} \times 25 \mu \mathrm{m}$ $\times 16.4 \mu \mathrm{m}$. As indicated by the arrows, it can be seen that the suspended proof masses are deflected downwards to some extent. The static displacements of the top surface of the proof masses below the device surface are approximately $40 \mathrm{~nm}$ (a), $30 \mathrm{~nm}$ (b) and $16 \mathrm{~nm}$ (c) for the three devices, respectively. The static displacements might be caused by the adhesion of the suspended graphene to the vertical walls at the microscopically rounded edges of the trenches (i.e. the $\mathrm{SiO}_{2}$ surfaces of the substrate and the proof mass) due to van der Waals forces. ${ }^{6}$ Preexisting folds in the graphene prior to the release of the proof mass that stretch out after the proof mass release may contribute to the measured static proof mass deflections. 


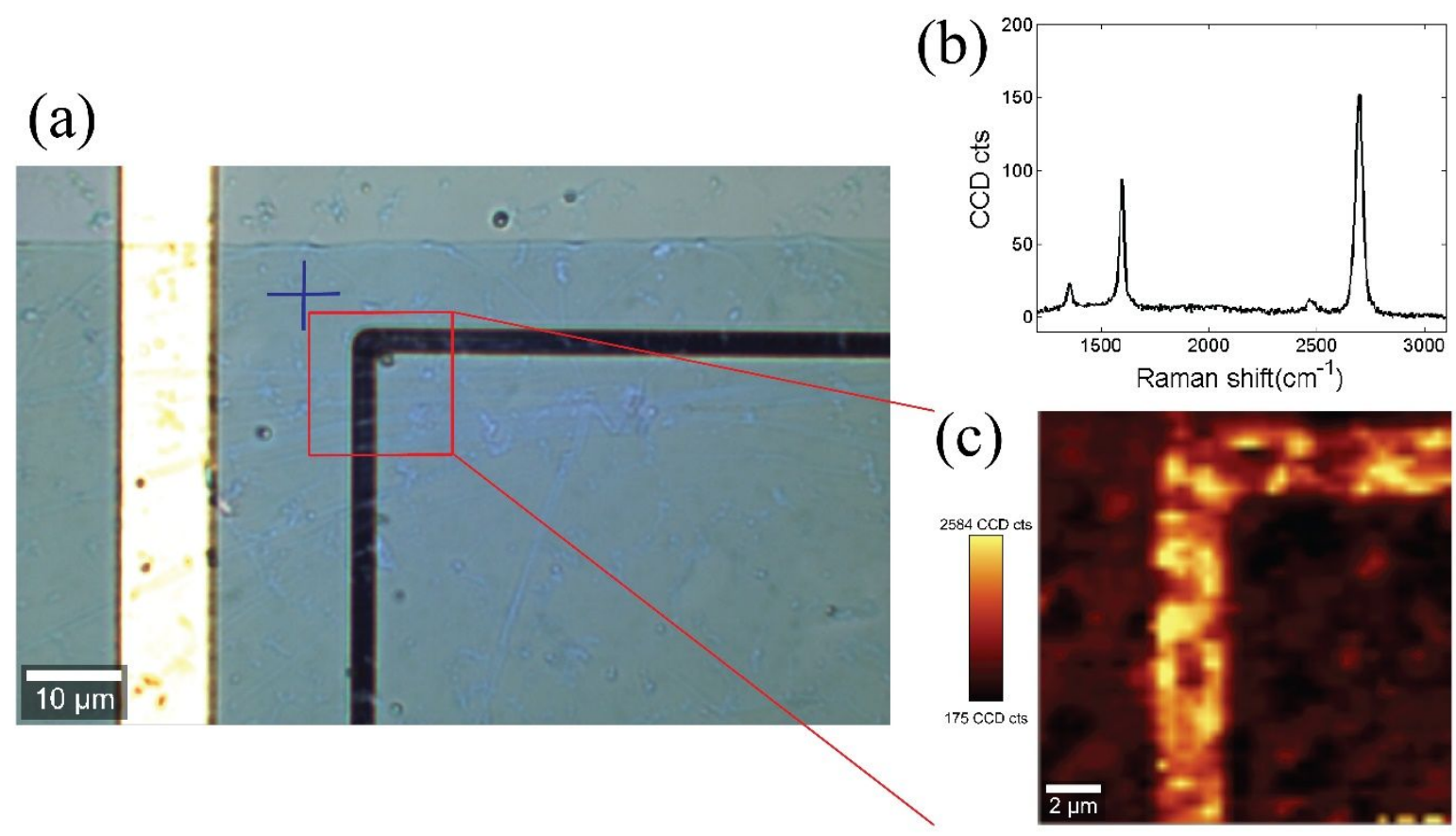

Figure S5. Raman spectroscopy of the double-layer graphene. (a) Optical microscopy image of a fabricated graphene device a $2 \mu \mathrm{m}$ wide trench and a silicon proof mass size of $100 \mu \mathrm{m} \times 100 \mu \mathrm{m} \times 16.4 \mu \mathrm{m}$. (b) Raman spectra of the area in (a) that is marked with the blue cross. The Raman spectrum shows typical characteristic peaks of graphene: The characteristic "G-peak" occurring at around $1595 \mathrm{~cm}^{-1}$ and the "2D-peak" occurring at around $2698 \mathrm{~cm}^{-1}$, which demonstrates the presence of graphene. The relatively weak "D-peak" occurring at around $1349 \mathrm{~cm}^{-1}$ illustrates that the quality of the obtained double-layer graphene decreased to some extent during the device fabrication process. (c) Map of the intensity of the 2D band of the area in (a) that is marked with the red rectangular box, illustrating that there are some PMMA residues on the suspended graphene membranes. 
(a)

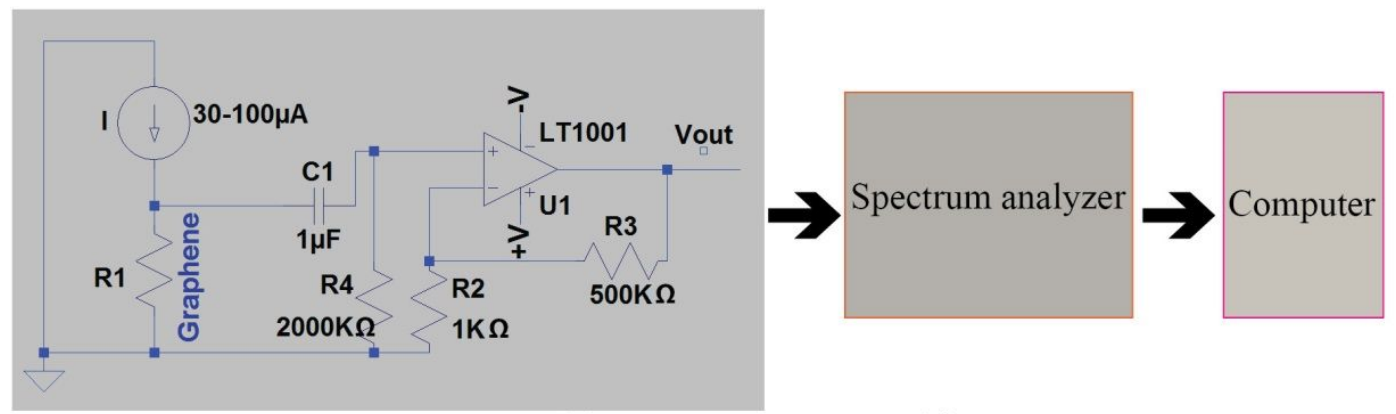

(b)

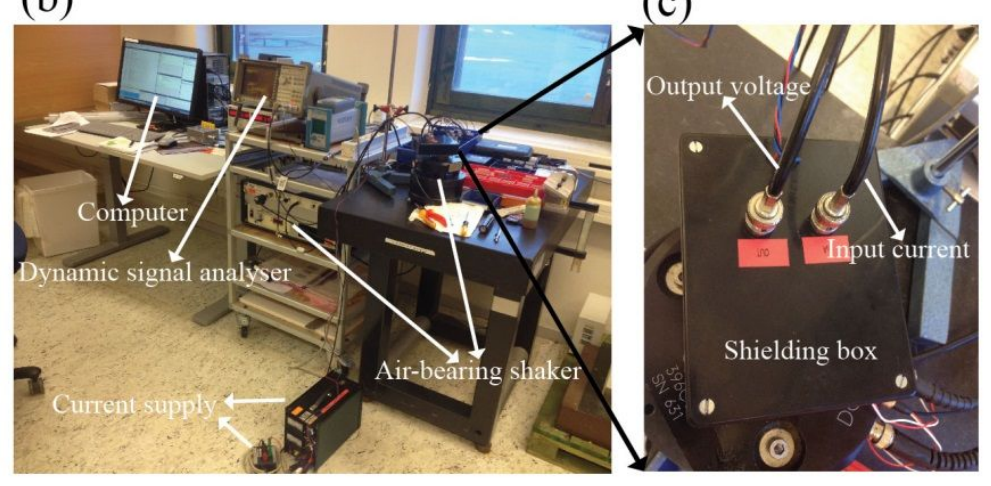

(d)

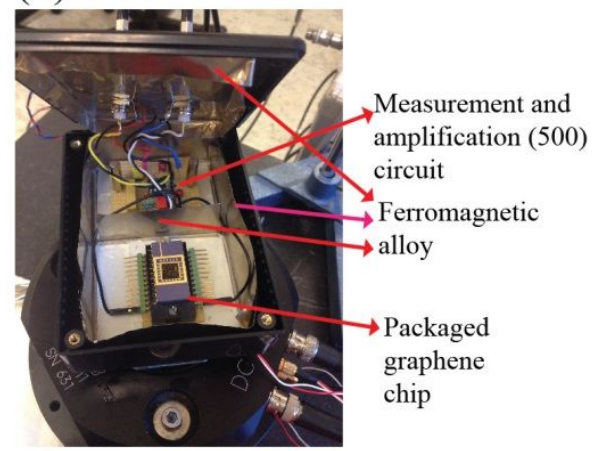

Figure S6. Measurement setup and circuit. (a) Schematic of the measurement circuit and the data acquisition setup. (b) Photograph of the measurement setup. (c) Electromagnetic shielding box including the packaged graphene devices and measurement circuits (signal amplification by a factor of 500), placed on the air-bearing shaker during acceleration measurements. Coaxial cables were connecting the measurement circuits inside the shielding box to a spectrum analyser. (d) View inside the shielding box for both electrostatic and magnetic shielding. A ferromagnetic alloy was used as the internal layer of the shielding box for magnetic shielding, separating the graphene devices from the measurement circuits and effectively reducing crosstalk between them. 
(a)

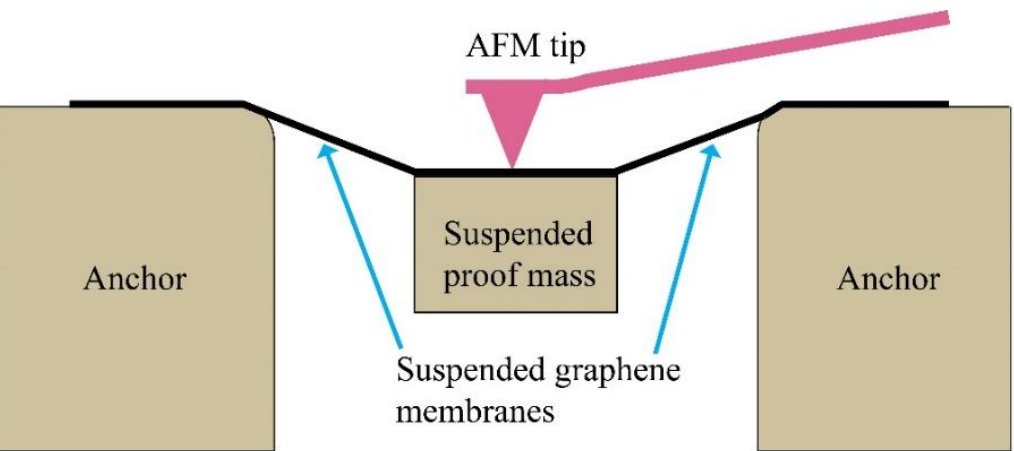

(b) AFM indentation measurements

(c)

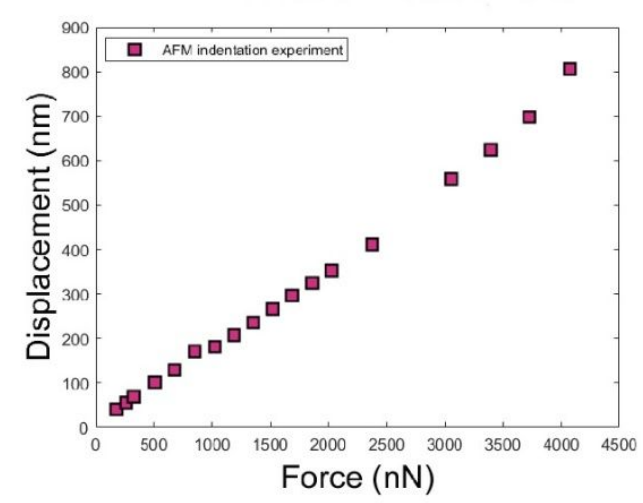

$10 \mu \mathrm{m}$

Figure S7. Force-displacement measurements of suspended graphene membranes with

attached proof mass using AFM tip indentation. (a) Schematic of force-displacement measurement by AFM indentation at the centre of the suspended proof mass. (b) Forcedisplacement measurements using AFM indentation of a device with a $3 \mu \mathrm{m}$ trench width and a proof mass size of $10 \mu \mathrm{m} \times 10 \mu \mathrm{m} \times 16.4 \mu \mathrm{m}$. When the AFM indentation force gradually increased from $178 \mathrm{nN}$ to $4070 \mathrm{nN}$, the displacement of the suspended proof mass increased from $40.7 \mathrm{~nm}$ to $806.7 \mathrm{~nm}$ (see Table S2). When the AFM indention force was further increased from $4070 \mathrm{nN}$ to $5051 \mathrm{nN}$, the graphene membrane with suspended proof mass ruptured and the suspended proof mass fell down (see Table S2). This indicates that suspended graphene membranes with attached proof mass are able to withstand an AFM indentation force of at least $4070 \mathrm{nN}$ without device failure. As a reference, the weight of a 10 $\mu \mathrm{m} \times 10 \mathrm{um} \times 16.4 \mu \mathrm{m}$ large proof mass results in a force of the order of $0.039 \mathrm{nN}$. (c) Highcontrast microscope image of suspended graphene membranes with attached proof mass of the device in (b). 
Table S1 Graphene device dimensions and extracted resistances of the different graphene sections of the device.

\begin{tabular}{|c|c|c|c|c|c|c|c|c|c|}
\hline $\begin{array}{l}\text { Device } \\
\text { number }\end{array}$ & a1 & a2 & a3 & a4 & a5 & a6 & a7 & b1 & B2 \\
\hline $\begin{array}{c}\text { Trench } \\
\text { width }(\mu \mathrm{m})\end{array}$ & 3 & 3 & 3 & 3 & 4 & 3 & 2 & 4 & 4 \\
\hline $\begin{array}{c}\text { Mass } \\
\text { dimensions } \\
(\mu \mathrm{m} \times \mu \mathrm{m} \\
\times \mu \mathrm{m})\end{array}$ & $\begin{array}{c}10 \times 10 \\
\times 16.4\end{array}$ & $\begin{array}{c}20 \times 20 \\
\times 16.4\end{array}$ & $\begin{array}{c}40 \times 40 \\
\times 16.4\end{array}$ & $\begin{array}{c}40 \times 40 \\
\times 16.4\end{array}$ & $\begin{array}{c}50 \times 50 \\
\times 16.4\end{array}$ & $\begin{array}{c}50 \times 50 \\
\times 16.4\end{array}$ & $\begin{array}{c}50 \times 50 \\
\times 16.4\end{array}$ & $\begin{array}{c}10 \times 10 \times \\
16.4\end{array}$ & $\begin{array}{c}40 \times 40 \times \\
16.4\end{array}$ \\
\hline $\begin{array}{l}\text { Output } \\
\text { voltage } \\
\mathrm{U}(\mathrm{mV})\end{array}$ & 1.1 & 1.124 & 0.406 & 0.322 & 1.706 & 0.481 & 0.344 & 0.176 & 0.364 \\
\hline $\begin{array}{c}\text { Overall } \\
\text { resistance } \\
\mathrm{R}(\Omega)\end{array}$ & 1110 & 600 & 600 & 400 & 440 & 990 & 580 & 476 & 725 \\
\hline $\begin{array}{c}\text { Sheet } \\
\text { resistance } \\
\mathrm{R}_{\mathrm{S}}(\Omega)\end{array}$ & $\sim 731.2$ & $\sim 423.7$ & $\sim 461.5$ & $\sim 307.6$ & $\sim 341.1$ & $\sim 783.3$ & $\sim 468.5$ & $\sim 382$ & $\sim 634$ \\
\hline $\begin{array}{c}\text { Resistance } \\
\text { of single } \\
\text { suspended } \\
\text { ribbon } \\
\mathrm{R}_{5}(\Omega)\end{array}$ & $\sim 137.1$ & $\sim 48.9$ & $\sim 30.1$ & $\sim 20.1$ & $\sim 23.53$ & $\sim 42$ & $\sim 17.35$ & $\sim 84.9$ & $\sim 52.83$ \\
\hline $\begin{array}{l}\text { Overall } \\
\text { resistance } \\
\text { change } \\
\Delta \mathrm{R}(\mathrm{m} \Omega)\end{array}$ & 22 & 22.48 & 8.12 & 6.44 & 34.12 & 9.62 & 6.88 & 3.52 & 7.28 \\
\hline $\begin{array}{c}\text { Resistance } \\
\text { change } \\
\text { of single } \\
\text { suspended } \\
\text { ribbon } \\
\Delta \mathrm{R}_{5}(\mathrm{~m} \Omega)\end{array}$ & $\sim 24.75$ & $\sim 19.22$ & $\sim 5.6$ & $\sim 4.44$ & $\sim 20.77$ & $\sim 6.28$ & $\sim 4.83$ & $\sim 12.52$ & $\sim 9.62$ \\
\hline $\begin{array}{c}\text { Overall } \\
\text { resistance } \\
\text { change rate } \\
\Delta \mathrm{R} / \mathrm{R}(\%)\end{array}$ & 0.002 & 0.00375 & 0.00135 & 0.00161 & 0.00775 & 0.001 & 0.0012 & 0.00074 & 0.001 \\
\hline $\begin{array}{c}\text { Resistance } \\
\text { change rate } \\
\text { of } \\
\text { Single } \\
\text { suspended } \\
\text { ribbon } \\
\Delta \mathrm{R}_{5} / \mathrm{R}_{5} \\
(\%)\end{array}$ & $\sim 0.0181$ & $\sim 0.0393$ & $\sim 0.0186$ & $\sim 0.0221$ & $\sim 0.0883$ & $\sim 0.015$ & $\sim 0.028$ & $\sim 0.0147$ & $\sim 0.0182$ \\
\hline
\end{tabular}


Table S2 Displacement of the suspended silicon proof mass at different applied AFM indentation forces.

\begin{tabular}{|c|c|c|}
\hline \multicolumn{3}{|c|}{$\begin{array}{l}\text { Proof mass size: } 10 \mu \mathrm{m} \times 10 \mu \mathrm{m} \times 16.4 \mu \mathrm{m} \\
\text { Trench width: } 3 \mu \mathrm{m} .\end{array}$} \\
\hline $\begin{array}{l}\text { AFM tip indentation force } \\
\qquad(\mathrm{nN})\end{array}$ & $\begin{array}{l}\text { Displacement of suspended } \\
\text { proof mass }(\mathrm{nm})\end{array}$ & $\begin{array}{l}\text { Status of graphene membrane } \\
\text { with suspended proof mass }\end{array}$ \\
\hline 178 & 40.7 & Intact \\
\hline 260 & 56 & Intact \\
\hline 328 & 68.7 & Intact \\
\hline 511 & 101.4 & Intact \\
\hline 679 & 129 & Intact \\
\hline 849 & 171 & Intact \\
\hline 1021 & 181.5 & Intact \\
\hline 1190 & 207.5 & Intact \\
\hline 1353 & 236 & Intact \\
\hline 1523 & 264.8 & Intact \\
\hline 1684 & 295.3 & Intact \\
\hline 1860 & 323.4 & Intact \\
\hline 2023 & 351.8 & Intact \\
\hline 2377 & 411.7 & Intact \\
\hline 3058 & 557.5 & Intact \\
\hline 3391 & 624 & Intact \\
\hline 3723 & 696.7 & Intact \\
\hline 4070 & 806.7 & Intact \\
\hline 5051 & - & Ruptured \\
\hline
\end{tabular}

